\title{
THE USE OF MEMBRANE TECHNIQUES IN SWIMMING POOL WATER TREATMENT
}

\author{
Edyta Łaskawiec', Marta Madej', Mariusz Dudziak', Joanna Wyczarska-Kokot ${ }^{1}$ \\ ${ }^{1}$ Institute of Water and Wastewater Engineering, Silesian University of Technology, Konarskiego 18, 44-100 \\ Gliwice, Poland, e-mail: madej.marta1@gmail.com, mariusz.dudziak@polsl.pl; joanna.wyczarska-kokot@ \\ polsl.pl; corresponding author: edyta.laskawiec@polsl.pl
}

Received: 2017.04.24

Accepted: 2017.05.31

Published: 2017.07.01

\begin{abstract}
The paper has determined the suitability of membrane processes (UF ultrafiltration, UF, and nanofiltration, NF) for the purification of waste streams, so-called backwash water, obtained from washing filtration beds in a swimming pool water system. The backwash water samples were taken from the circuits located in two indoor facilities with a different purpose of the basins. Moreover, the samples were characterized by varying quality, as described by selected physicochemical parameters (such as turbidity and ultraviolet absorbance UV254). Commercial membranes were used for the tests. The transport-separation properties of the membranes were determined based on the volumetric flux of the permeate. In addition, backwash water samples before and after the membrane process were subjected to toxicological assessment using the Microtox $^{\circledR}$ screening test. The performed processes contributed to a significant reduction in turbidity and the value of UV254 ultraviolet absorbance, both in the ultrafiltration and nanofiltration processes. Whereas, significant differences in transport properties were noted within individual processes. A great influence of backwash water quality, including physicochemical parameters, on the course and results of the membrane filtration processes was demonstrated. In all of the nanofiltration cycles carried out, the removal of the toxic properties of the backwash water with respect to bacteria in the Microtox ${ }^{\circledR}$ test was found. Nevertheless, samples with high values of resultant physicochemical parameters after the ultrafiltration process were still characterized by high toxicity. Pressure membrane processes show high effectiveness in the removal of contaminants from backwash water. However, it is necessary to introduce supporting processes aimed at reducing membrane pore blocking by deposits and organic compounds, and in the case of ultrafiltration, assuring the safety of the purified stream in terms of the toxicological effect.
\end{abstract}

Keywords: pressure membrane processes, ultrafiltration, nanofiltration, toxicological assessment

\section{INTRODUCTION}

Varying in terms of substance separation processes, pressure membrane processes enable the separation of contaminants at a molecular level, owing to which they presently find wide application, e.g., in ultra-clean water preparation processes, for purification of industrial waste stream and for the removal of micro-contaminants from various water streams, including municipal sew- age [Kamińska et al, 2016; Bodzek 2013]. The ultrafiltration process relies on the sieve transport mechanism, and retained particles are of sizes larger than the membrane pore diameter. Ultrafiltration membranes are able to retain fine suspensions, colloids, bacteria and viruses. It is accepted that components of a molecular mass above 500 Da can be separated from a water stream [Bodzek and Konieczny 2005]. In turn, the nanofiltration process is distinguished by a high retention 
of ions of a valence of 2 and more, and organic compounds of a molecular mass above 200-300 Da. Nanofiltration constitutes a process, in which the separation mechanism relies on the phenomena of dissolution and diffusion in the membrane [Bodzek and Konieczny 2005; Al. Zahrania and Mohammad 2014]. The huge demand for water and the high costs of water intake and sewage discharge make the interest in the possibilities of water recovery from the waste streams constantly grow [Bodzek and Konieczny 2005; Wyczarska-Kokot 2015].

The processes of surface coagulation and filtration in pressure beds provide basic tools for maintaining the required physicochemical parameters of water in swimming pool facilities. To maintain the properties of filtration beds, it is necessary to regularly flush them with a water and/or air stream in the direction opposite to the water flow direction during the standard filtration process [Piechurski 2011]. The waste stream, so-called backwash water, occurring in the flushing process is distinguished by large contents of suspension and dissolved substances. Particularly problematic from the perspective of the management of backwash water, and so its recirculation, is its contents of disinfection by-products and contaminants present in chemicals used in the surface coagulation process, which often impart a toxic character to the backwash water stream [McCormick et al 2010; Leszczyńska and Sozański 2009; Meriḉ et al 2005].

Taking into consideration of the properties of pressure membrane processes, an attempt was made to employ them for the purification of swimming pool water system backwash water. This paper reports the results of the tests of purification of backwash water samples taken from swimming pool water systems in the ultra- and nanofiltration processes based on selected physicochemical processes (i.e. turbidity and ultraviolet absorbance). In addition, the analysis was supplemented with a toxicological assessment using the Microtox ${ }^{\circledR}$ bacterial test that was aimed at documenting any changes in the quality of backwash water before and after the membrane filtration process.

\section{MATERIALS AND METHODS}

\section{Analytical procedures}

In order to assess the quality of both the backwash water and the filtrates, selected physicochemical parameters were measured. The mea- surement of the conductivity (PWC) and reaction $(\mathrm{pH})$ of test samples was done with an inoLab ${ }^{\circledR}$ 740 multi-parameter meter (WTW, Measuring and Analytical Technical Equipment). The ultraviolet absorbance at a wavelength of $254 \mathrm{~nm}$ was measured using a UV VIS Cecil 1000 supplied by Analytik Jena AG, with a cuvette optical pathlength of $1 \mathrm{~cm}$. The UV254 value was determined based on the measurement method presented by US EPA [Potter and Wimsatt 2009], and the final analysis result was expressed in $\mathrm{m}^{-1}$. The value of UV254 ultraviolet absorbance is a substitute parameter for the total organic carbon (TOC) analysis, providing information about the potential of formation of disinfection by-products. It should be remembered, however, that this measurement is not completely selective [Mołczan et al 2006]. A Pocket Colorimeter ${ }^{\mathrm{TM}}$ II by $\mathrm{Hach}^{\circledR}$ portable instrument was used for determining the concentration of total and free chlorine by the colorimetric method. Moreover, the measurement of the ammonium and nitride nitrogen concentrations was taken using a Photolyser 400 (Dinotec) tester. For the determination of the turbidity of samples, an EUTECH Instruments Turbidimeter, Model TN100, was employed. Each of the presented measurements are made in a single repetition.

\section{Toxicological assessment of the effects of the conducted processes}

The backwash water test samples before and after the membrane filtration process were additionally subjected to toxicological assessment using the Microtox ${ }^{\circledR}$ bacterial test. This was aimed at assessing the effectiveness of the employed membrane processes in removing toxic compounds occurring in the backwash water. The toxicity test was performed following the Screening Test procedure of the MicrotoxOmni system in a Microtox analyzer, Model 500, manufactured by Tigret Sp. z. o. o., performing the function of both an incubator and a photometer. The percentage of bioluminescence inhibition relative to the control sample (bacteria not subjected to a potential toxicant) was measured after 5 and 15 minutes' exposure times. The obtained results were assessed based on the toxicity classification system shown in Table 3 [Grabińska-Sota 2015, Hsieh et al 2008]. Before proceeding with testing, the samples were subjected to the repeated measurement of free chlorine concentration. The presence of free chlorine may have a profound influence on the increased level of sample toxicity resulting 
Table 1. Toxicity classification system

\begin{tabular}{|c|c|}
\hline Effect, $\%$ & Toxicity class \\
\hline$<25$ & non-toxic \\
\hline $25-50$ & low toxicity \\
\hline $50.1-75$ & toxic \\
\hline $75.1-100$ & high toxicity \\
\hline
\end{tabular}

from the destructive action of chlorine upon Aliivibrio fischeri bacteria. The measurement did not show the presence of free chlorine in the samples, because the appropriate time interval had been maintained between sampling and performing the biotest. The standard deviation of the Microtox ${ }^{\circledR}$ test ranges from $6 \div 10 \%$.

\section{Characterization of backwash water tested}

The subject of testing were waste water (backwash water) streams originating from the flushing of filtration beds located in facilities of a varying character of use. The swimming pool circuit under investigation is a swimming lesson basin located in a primary school. During fortyfive minutes' lesson, 8 to 25 pupils use the swimming pool. The second investigated circuit, which included a hot tub, constituted an element located in a general-access aqua park facility with a high load of 300 to 500 people a day. The water treatment facilities in the facilities operate based on the same processes, which include: pre-filtration, surface coagulation, filtration on sand-anthracite bed, heating up the water in heat exchangers, disinfection with sodium hypochlorite, and the correction of $\mathrm{pH}$. The facilities are supplied with water from the municipal water-pipe networks. The backwash water is discharged, together with domestic sewage, to the sewage system. Flushing of filtration beds is done at a varying frequency, depending on the facility. In the case of the swimming pool circuit, it is done each time after finishing sports classes on a given day, while for the hot tub circuit, 48 hours had elapsed since its last flushing. The examined physicochemical parameters of the backwash water are summarized in Table 1. The examined backwash water was distinguished by variable quality, especially in terms of the values of turbidity and UV254 ultraviolet absorbance, which were the subject of analysis in the assessment of the sorption capacity of the tested membranes.

\section{Membrane filtration methodology}

Flat commercial ultrafiltration and nanofiltration membranes manufactured by GE Osmonics Inc. (USA), differing in operation process parameters, were used in the tests. The membrane characteristics and parameters are given in Table 2 . Moreover, the membranes used were characterized by high resistance to chloride present in the backwash water tested.

The membranes were placed in a $380 \mathrm{~cm}^{3}$ cell that allowed the process to be conducted in a unidirectional system. Before starting filtration, the new membranes were conditioned by filtrating deionized water until the permeate volumetric flux stabilized. The proper filtration process was conducted until $50 \%$ of the feed were received, by using a trans-membrane pressure of $0.2 \mathrm{MPa}$ for ultrafiltration, and 2.0 MPa for nanofiltration. At the same time, selected physicochemical parameters were verified in successively received $25 \mathrm{~cm}^{3}$-volume permeates and the magnitudes of the permeate volumetric flux were determined, each time taking six measurements.

Table 2. Description of the physicochemical test of swimming pool circuit backwash water

\begin{tabular}{|c|c|c|c|}
\hline \multirow[b]{2}{*}{ Physicochemical parameters } & \multirow[b]{2}{*}{ Unit } & \multicolumn{2}{|c|}{ Test backwash water } \\
\hline & & $\begin{array}{l}\text { Swimming lesson basin } \\
\text { circuit }\end{array}$ & Hot tub circuit \\
\hline Reaction $(\mathrm{pH})$ & - & 6.25 & 7.13 \\
\hline Conductivity (PWC) & $\mu \mathrm{S} / \mathrm{cm}$ & 1380.00 & 1939.00 \\
\hline Turbidity & NTU & 30.90 & 75.30 \\
\hline $\mathrm{UV}_{254}$ ultraviolet absorbance & $\mathrm{m}^{-1}$ & 58.40 & 7.50 \\
\hline Total chlorine & $\mathrm{mgCl}_{2} / \mathrm{dm}^{3}$ & 2.48 & 0.67 \\
\hline Free chlorine & $\mathrm{mgCl}_{2} / \mathrm{dm}^{3}$ & 0.33 & 0.05 \\
\hline Bonded chlorine & $\mathrm{mgCl}_{2} / \mathrm{dm}^{3}$ & 2.15 & 0.62 \\
\hline Nitrate nitrogen & $\mathrm{mgN}-\mathrm{NO}_{3} / \mathrm{dm}^{3}$ & Non-receipt of data & 55.00 \\
\hline Ammonium nitrogen & $\mathrm{mgN}-\mathrm{NH}_{4} / \mathrm{dm}^{3}$ & Non-receipt of data & 0.48 \\
\hline $\begin{array}{l}\text { Bioluminescence inhibition - exposure time } \\
\text { of } 5 \mathrm{~min}-15 \mathrm{~min}\end{array}$ & $\%$ & $100-100$ & $68.06-70.06$ \\
\hline
\end{tabular}


Table 3. Characteristics of the membranes and the operating process parameters

\begin{tabular}{|c|c|c|c|c|c|c|c|}
\hline Process & $\begin{array}{l}\text { Membrane } \\
\text { symbol }\end{array}$ & Membrane material & $\begin{array}{l}\text { Molecular } \\
\text { mass cut- } \\
\text { off, Da }\end{array}$ & $\begin{array}{c}\text { Process } \\
\text { pressure, } \\
\mathrm{MPa}\end{array}$ & $\begin{array}{l}\text { Membrane } \\
\text { active surface } \\
\text { area, } \mathrm{m}^{2}\end{array}$ & $\begin{array}{c}\text { Deionized } \\
\text { water permeate } \\
\text { volumetric flux, } \mathrm{J}_{\mathrm{w}} \\
10^{-5} \mathrm{~m}^{3} / \mathrm{m}^{2} \cdot \mathrm{s}\end{array}$ & $\begin{array}{l}\text { Permeate } \\
\text { recovery, \% }\end{array}$ \\
\hline UF & MW & $\begin{array}{l}\text { Polyacrylonitrile } \\
\text { (PAN) }\end{array}$ & 50000 & 0.2 & \multirow[b]{2}{*}{0.375} & 5.46 & \multirow[b]{2}{*}{50} \\
\hline NF & $\mathrm{HL}$ & $\begin{array}{l}\text { Thin film composite } \\
\text { (TFC) (skin layer - } \\
\text { polyamide (PA)) }\end{array}$ & $150-300$ & 2.0 & & 3.03 & \\
\hline
\end{tabular}

The assessment of the transport properties of the membranes in the filtration processes was made based on the volumetric flux of deionized water, $\mathrm{J}_{\mathrm{w}}$ (during conditioning the membrane with water), and the permeate, $\mathrm{J}_{\mathrm{v}}$ (the proper filtration process), from the following equation:

$$
J_{w}=\frac{v}{F \cdot t}, \frac{m^{3}}{m^{2} \cdot s}
$$

where: $V$ - volume of water of permeate, $\mathrm{m}^{3}$;

$F$ - membrane active surface area, $\mathrm{m}^{2}$;

$t$ - filtration time, $s$.

To assess the separation properties of membranes, the retention $(\mathrm{R})$ was determined, whose value was determined based on the reduction in the values of respective contamination indices:

$$
R=\left(1-\frac{c_{p}}{c_{n}}\right), \%
$$

where: $c_{p}-$ concentration (index value) of contaminants in the permeate stream, $c_{n}$ - concentration (index value) of contaminants in the feed.

The intensity of the reduction in membrane transport capacity (membrane pore blocking degree) was determined by calculating the value of the relative permeate volumetric flow rate:

$$
\alpha=\frac{J_{w}}{J_{v}}
$$

where: $J_{w}$-value of the permeate volumetric flux at the sixth measurement point, $\mathrm{m}^{3} / \mathrm{m}^{2} \cdot \mathrm{s}$; $J_{v}$ - value of the deionized water volumetric flux, $\mathrm{m}^{3} / \mathrm{m}^{2} \cdot \mathrm{s}$.

\section{INVESTIGATION RESULTS}

The employed filtration membrane showed high effectiveness in removing contaminants from backwash water taken from the swimming lesson basin circuit. In terms of both turbidity and the reduction of UV254 ultraviolet absorbance (Figure 1a), the average values of the contamination retention coefficients exceeded $99 \%$ (which was presented by using a column chart). However, during the course of the process, a considerable reduction in the value of the permeate volumetric flux occurred (which was presented by using a line chart). Initially, the value of the relative permeability coefficient (at $8 \%$ permeate stream recovery) amounted to 0.87 , while at the last measurement point of that filtration cycle ( $50 \%$ recovery), the value of this parameter decreased to 0.57 , which indicates a reduction in process efficiency by approx. $43 \%$. The worsening of the membrane transport capacity was due to the blocking of membrane pores by deposits and suspended particulates present in the backwash water.

The characteristics of the transport-separation capacity of the nanofiltration membrane used with respect to the purified backwash water taken from the swimming lesson basin circuit is shown in Figure 1b. A several-percent decrease in retention coefficient values, compared to the UV254 ultraviolet absorbance, was noted. In should be noted, however, that membranes of this type remove a much wider range of contaminants than ultrafiltration membranes do, especially in respect of small-molecule compounds [Bodzek and Konieczny 2005].

The nanofiltration was characterized by much lower values of the deionized water volumetric flux, compared to the ultrafiltration. In addition, the presence of a deposit and large-molecular compounds in the backwash water contributed to a significant worsening of the membrane transport capacity. The value of the relative permeability coefficient decreased from 0.37 (at $8 \%$ stream recovery) to 0.26 (at 50\% stream recovery).

The backwash water quality had a significant influence on the transport-separation properties of the membranes used. Figure 2 illustrates the effects of the filtration of backwash water coming 

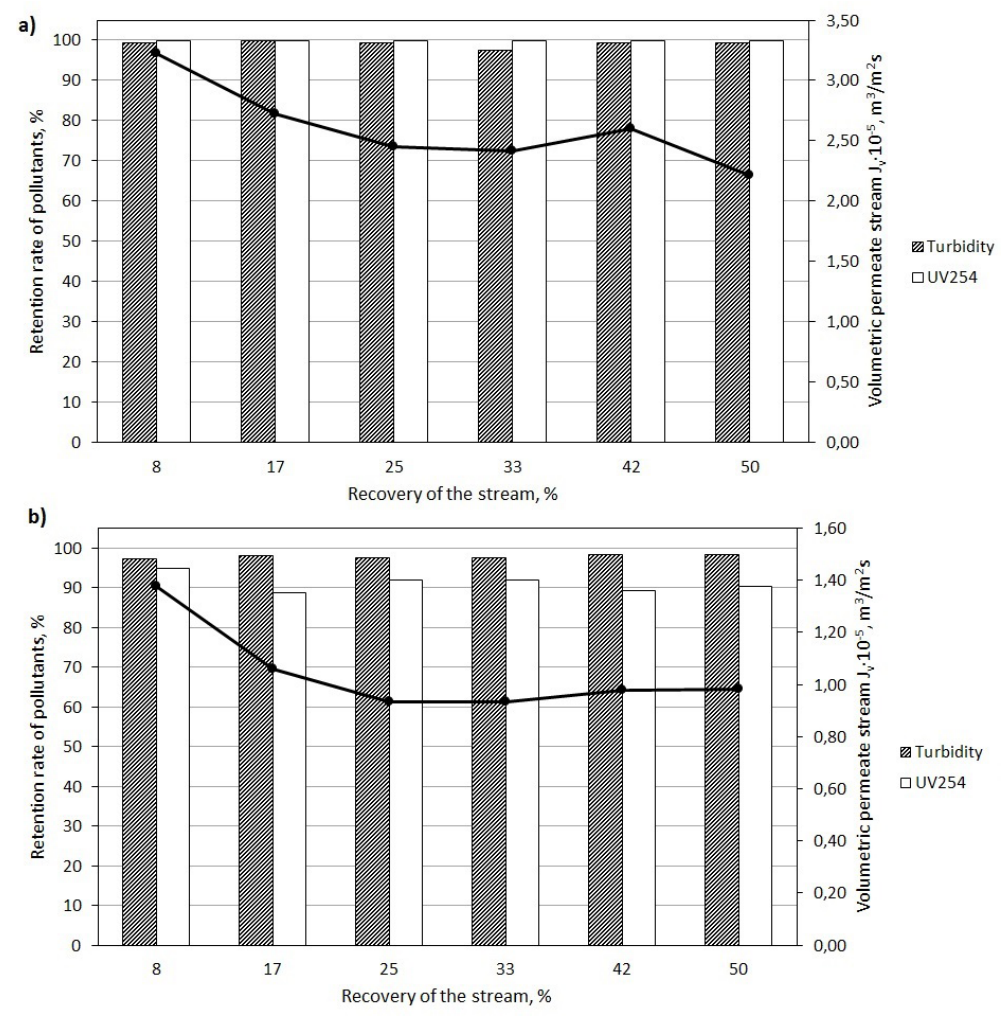

Fig. 1. The transport and separation properties of the membranes in the filtration of the swimming lesson basin circuit backwash water for: a) the ultrafiltration process b) the nanofiltration process
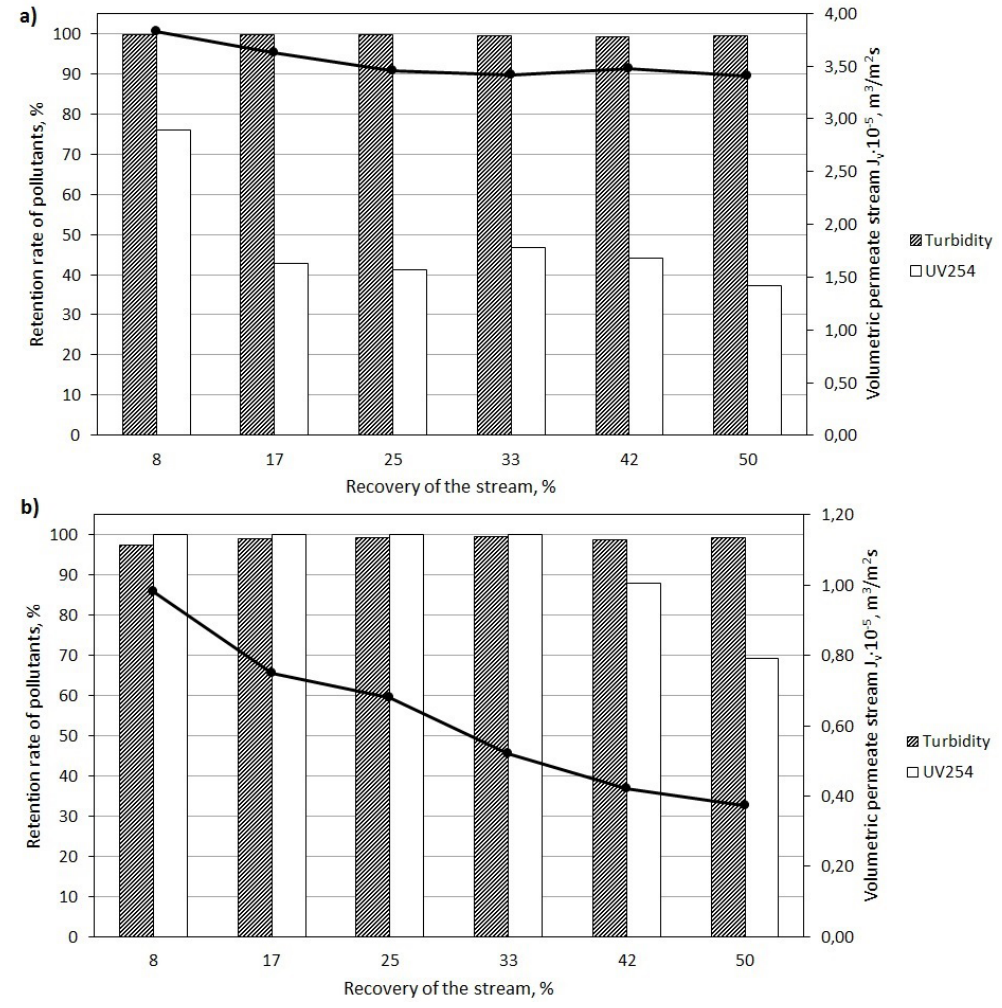

Fig. 2. The transport and separation properties of the membranes in the filtration of the hot tub circuit backwash water for: a) the ultrafiltration process b) the nanofiltration process 
from the hot tub circuit, which was distinguished by a lower value of both turbidity and UV254 ultraviolet absorbance. During ultrafiltration, high values of the turbidity retention coefficient (about 99\%) were obtained (which was presented by using a column chart). In contrast, a significant lowering of the membrane separation capacity in terms of ultraviolet absorbance, with the retention coefficient value ranging from 50 to $41 \%$. During the filtration of backwash water with higher deposit and suspended particulate contents (a higher turbidity value), a so-called secondary membrane might have formed, which could contribute to an increase in membrane separation capacity during filtration [Dudziak 2013]. In turn, the lower backwash water turbidity value (the hot tub circuit) contributed to the membrane retaining its good transport capacity during ultrafiltration. The relative permeability coefficients in the filtration cycle for the hot tube circuit backwash water were contained in the range of 0.97 (at $8 \%$ permeate stream recovery) $\div 0.86$ (at $50 \%$ ). The nanofiltration process in this case, too, was characterized by high contaminant retention coefficient values (Figure 2b). The aforementioned differences in physicochemical parameter values significantly affected the transport capacity of the membrane.
The value of the relative permeability coefficient was in this process contained in the range from 0.25 to 0.09 . This is indicative of the presence of the group of compounds that did not add up to the high turbidity value, yet caused intensive blocking of nanofiltration membrane pores.

\section{Toxicological assessment of backwash water}

At the last stage of the investigation, the toxicological assessment of test samples of the stream of backwash water both before and after the purification process by the ultrafiltration and nanofiltration processes was made. From the results of the Microtox ${ }^{\circledR}$ test (Figure 3) it was found that the process of nanofiltration had removed the majority of substances responsible for bacterial bioluminescence inhibition from the backwash water. This value for the swimming lesson basin circuit was reduced from $100 \%$ in the raw samples to approx. $28 \%$ in the samples after filtration (Figure $3 \mathrm{a}$ ). On the other hand, in the hot tub circuit samples, the bioluminescence inhibition value for the raw backwash water was lower, amounting to $70 \%$, and the nanofiltration process reduced this value to $6.44 \%$. The above-mentioned values represent results for 15 minutes' time of exposing
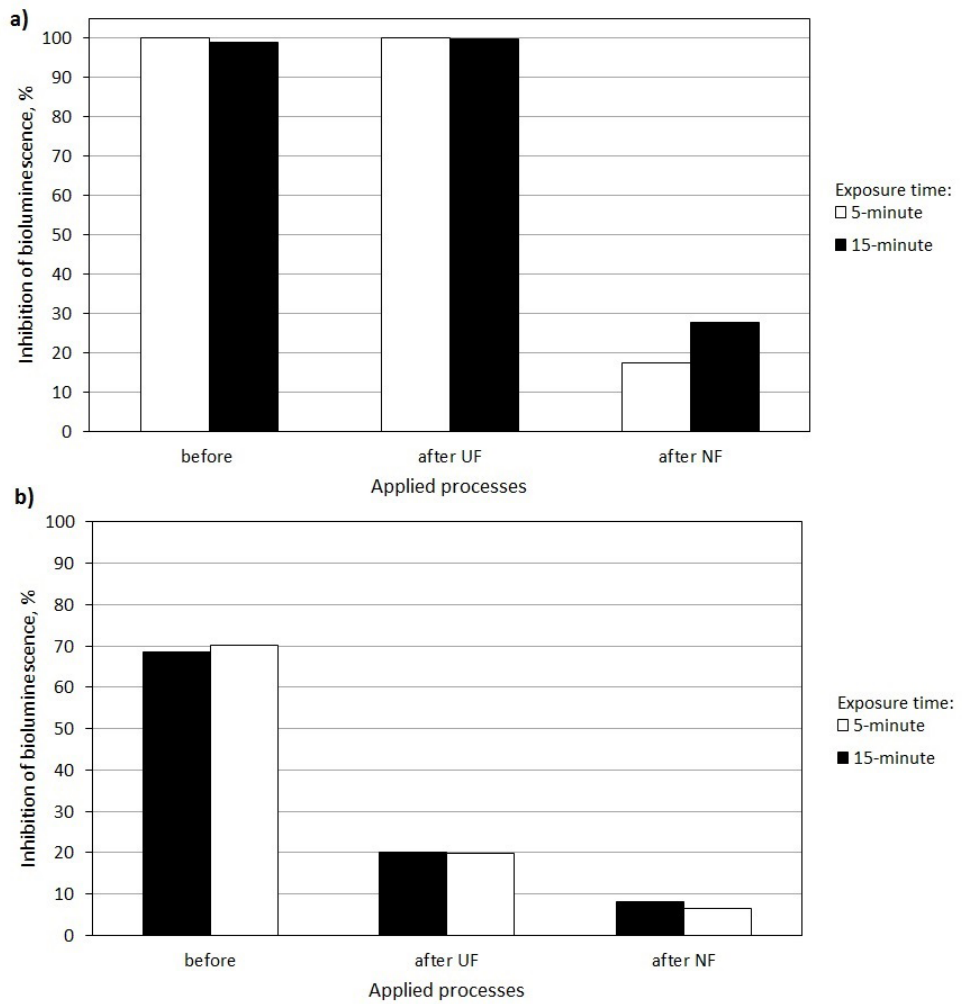

Fig. 3. Toxicological assessment of samples using Microtox ${ }^{\circledR}$ bioassay for backwash water from: a) the swimming pool circuit $b$ ) the hot tub circuit 
bacteria to the action of the backwash water samples; whereas, the value of this parameter did not have any major effect on the observed relationship. In the samples of backwash water after the ultrafiltration process, large differences in biotest results were noted, depending on the circuit tested. This process did not reduce the toxic action of the sample coming from the swimming lesson basin, with respect to Aliivibrio fischeri bacteria. However, it minimized the bioluminescence inhibition value down to a level recognized as non-toxic for backwash water coming from the hot tub circuit $(19.85 \%)$. In spite of the obtained high contaminant retention coefficient values for the process of ultrafiltration of the swimming pool backwash water, the toxicological assessment showed that the samples still contained components that might be dangerous to living organisms.

\section{CONCLUSIONS}

The membrane processes used in the investigation significantly improved the quality of backwash water from the swimming pool system circuits. Nanofiltration showed a higher contaminant separation efficiency, but a definitely lower hydraulic capacity, compared to ultrafiltration. On this basis it can be stated that it is necessary to pre-process the backwash water prior to membrane filtration (e.g. by employing a coagulation and/or sedimentation process). A significant effect on the UF process efficiency was exhibited by the backwash water quality. When used on a commercial scale, pressure membrane processes can enable the recovery of water from processed swimming pool circuit backwash water. To this end, however, it is necessary to introduce supporting processes that will improve the transport capacity of the membrane and extend its life. For the ultrafiltration process, the improvement in carrying out the process in the aspect of assuring the safety of the purified stream in terms of the toxicological effect is also indispensable.

\section{Acknowledgements}

The study was carried out within the framework of the Faculty's research grant for young scientists (BKM-536/RIE-4/15) "Quality assessment of swimming pool water aided with ecotoxicology tools".

\section{REFERENCES}

1. Al Zahrania S., Mohamad A. W., 2014. Challenges and trends in membrane technology implementation for produced water treatment: A review. Journal of Water Process Engineering, no. 4, 107-133.

2. Bodzek M., 2013. A review of the possibilities for using membrane techniques in the removal of microorganisms and organic contaminations from the aqueous medium [in Polish]. Inżynieria i Ochrona Środowiska, 16(1), 5-37.

3. Bodzek M., Konieczny K., 2005. The use of membranes processes in water treatment [in Polish]. Projprzem-Eko Publishing House, Bydgoszcz.

4. Dudziak M., 2013. Separation of estrogenic microcontaminants using high-pressure membrane techniques [in Polish]. University Press of the Silesian University of Technology, Gliwice.

5. Grabińska-Sota E., 2015. Ecotoxicological testing in environmental protection [in Polish]. University Press of the Silesian University of Technology, Gliwice.

6. Hsieh C.Y., Tsai M.H., Rayan D.K., Pancorbo O.C., 2008. Toxicity of the 13 priority pollutant metals to Vibrio fischeri in the Microtox ${ }^{\circledR}$ chronic toxicity test. Science of The Total Environment, 320(1), 37-50.

7. Kamińska G., Dudziak M., Bohdziewicz J., Kudlek E., 2016. Assessment of the effectiveness of removing selected biologically active substances by the monofiltration process [in Polish]. Proceedings of EC Opole, 10(1), 155-164.

8. Leszczyńska M., Sozański M.M., 2009. Harmfulness and toxicity of deposits and washings from the water treatment process [in Polish]. Ochrona Środowiska i Zasobów Naturalnych, no. 40, 575-585.

9. McCormick N.J. porter M., Walsh M.E., 2010. Disinfection by-products in filter backwash water: implications to water quality in recycle designs. Water Research, no. 44, 4581-4589.

10. Meriç S., Selçuk H., Belgiorno V., 2005. Acute toxicity removal in textile finishing wastewater by Fenton's oxidation, ozone and coagulation-flocculation processes, Water Research, 9(6), 1147-1153.

11. Mołczan M., Szlachta M., Karpińska M., Biłyk A., 2006. The use of specific ultraviolet absorbance (SUVA) in water quality assessment [in Polish]. Ochrona Środowiska, 28(4), 11-16.

12. Piechurski F.G., 2011. Technical solutions of devices for water purification in public swimming pools [in Polish]. Technologia Wody, no. 5, 22-34.

13. Potter B. Wimsatt J., Determination of total organic carbon and specific UV absorbance at $254 \mathrm{~nm}$ in source water and drinking water, 2009, EPA Document, Method 415.3.

14. Wyczarska-Kokot J., 2015. Exploring the possibilities for the management of swimming pool circuit backwash water [in Polish]. Proceedings of ECOpole, $9(2), 803-813$. 